\title{
A Study of Nonstationary Wind Effects on a Full-Scale Large Cooling Tower Using Empirical Mode Decomposition
}

\author{
X. X. Cheng, ${ }^{1,2}$ J. Dong, ${ }^{1}$ Y. Peng, ${ }^{1}$ L. Zhao, ${ }^{2}$ and Y. J. Ge ${ }^{2}$ \\ ${ }^{1}$ College of Civil Engineering, Nanjing Tech University, Nanjing 211816, China \\ ${ }^{2}$ State Key Laboratory for Disaster Reduction in Civil Engineering, Tongji University, Shanghai 200092, China \\ Correspondence should be addressed to J. Dong; dongjun@njtech.edu.cn
}

Received 7 January 2017; Revised 31 March 2017; Accepted 19 April 2017; Published 11 May 2017

Academic Editor: Sandro Longo

Copyright (c) 2017 X. X. Cheng et al. This is an open access article distributed under the Creative Commons Attribution License, which permits unrestricted use, distribution, and reproduction in any medium, provided the original work is properly cited.

\begin{abstract}
Wind effects on structures obtained by field measurements are often found to be nonstationary, but related researches shared by the wind-engineering community are still limited. In this paper, empirical mode decomposition (EMD) is applied to the nonstationary wind pressure time-history samples measured on an actual 167-meter high large cooling tower. It is found that the residue and some intrinsic mode functions (IMFs) of low frequencies produced by EMD are responsible for the samples' nonstationarity. Replacing the residue by the constant mean and subtracting the IMFs of low frequencies can help the nonstationary samples become stationary ones. A further step is taken to compare the loading characteristics extracted from the original nonstationary samples with those extracted from the processed stationary samples. Results indicate that nonstationarity effects on wind loads are notable in most cases. The passive wind tunnel simulation technique based on the assumption of stationarity is also examined, and it is found that the technique is basically conservative for use.
\end{abstract}

\section{Introduction}

Strong winds do not necessarily possess the easy-to-understand stationary features. Hurricanes, tornadoes, downbursts, and gust fronts are nonstationary in nature and are often highly transient [1], which might cause destructive wind effects on structures. Different from those extreme wind events, the common strong atmospheric boundary layer $(\mathrm{ABL})$ winds are generally assumed to be stationary. Based on this assumption, the passive $\mathrm{ABL}$ wind tunnels, which can only generate standard stationary flows, are widely employed to obtain the wind effects on structures. In reality, full-scale ABL wind fields lack stationarity as compared with those simulated in the wind tunnel [2], and the speed and the direction of the realistic $\mathrm{ABL}$ winds are sometimes found unsteady [3]. In this regard, the assumption of stationarity for ABL wind fields should be reconsidered and efforts should be made to study the wind effects obtained on structures in nonstationary wind fields using powerful tools.

On the whole, two approaches have been used for analyzing data of nonstationary features: wavelet transform $[4,5]$ and Hilbert-Huang transform $[6,7]$. In a nutshell, wavelet transform (WT) allows a multiresolution representation of a process and provides a flexible time-frequency window that narrows in frequency domain to observe high frequency energy content and broadens in frequency domain to capture low frequency phenomena, while Hilbert-Huang transform (HHT) is to decompose the signal using the empirical mode decomposition (EMD) into intrinsic mode functions (IMFs) which have well-behaved Hilbert transform properties. Comparing WT to HHT, $\mathrm{Li}$ and $\mathrm{Wu}$ [7] found that although the WT can decouple the responses of a MDOF system into individual modes, the validity of this decoupling procedure is strictly dependent on the wavelet frequency resolution. Limited by the size of the basic wavelet functions, the application of the wavelet-based analysis becomes difficult with modal superposition at high-frequencies, especially when the high vibration modes of the signals are not separated far enough. However, the EMD algorithm in HHT is based on direct extraction of the signal's energy associated with various intrinsic time scales. The time scale in the EMD is inherent to the original signal itself as the decomposition procedure in the EMD is self-adaptive and is not affected by decomposition functions as the wavelet transform does. In 

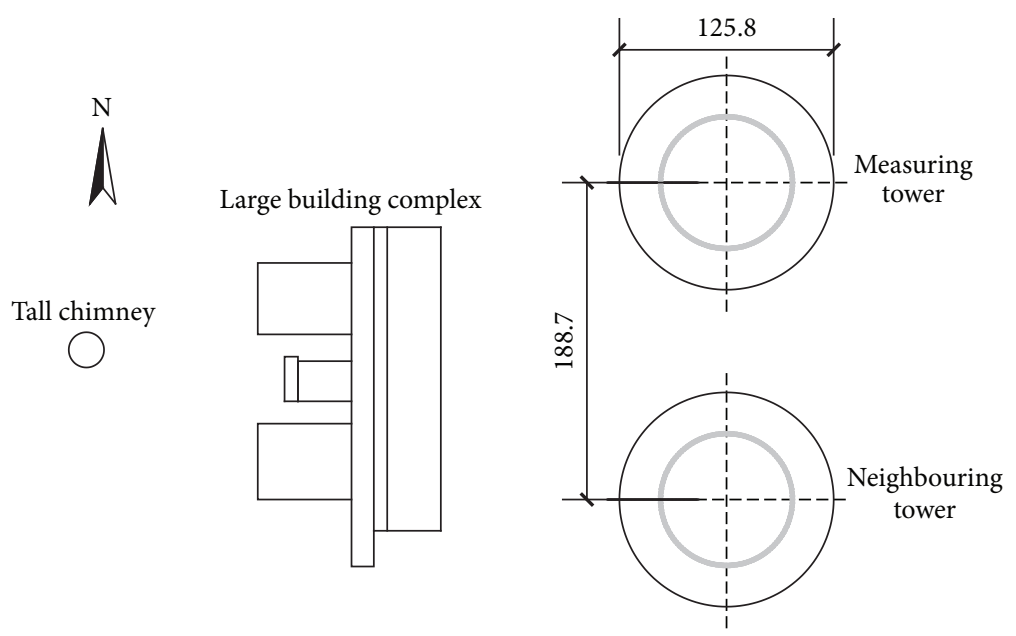

FIGURE 1: Site plan of Peng-cheng electric power station (unit: m).

this regard, HHT has its advantage in dealing with signals of densely spaced high vibration modes, including many wind effects measured in the field (e.g., the wind pressure timehistory samples measured by Cheng et al. [3] on a full-scale large cooling tower whose substantial energies accumulate at high-frequencies).

To this end, this paper utilizes EMD to process the typical wind pressure time-history samples measured on the 167$\mathrm{m}$ high Peng-cheng cooling tower. Loading characteristics, including the mean and fluctuating wind pressure distributions, the power-spectral density, the coherence function, the probability density function, and the spatial correlation, are extracted from the original full-scale wind pressure time-history samples of nonstationarity and the processed stationary samples, respectively. By comparison, the nonstationarity effects on wind loads are appreciated. Besides, many researchers are aware of the deficiency of the passive wind tunnel technique in simulating the nonstationary features of the realistic $\mathrm{ABL}$ flow fields $[2,8]$. However, no one has actually quantified the influence of the deficiency on model test results. In this regard, the obtained full-scale loading characteristics are also compared with the model test results. Through these works, one can gain some insights into the nature of the realistic wind effects and the similarity problem with the traditional passive wind tunnel simulation technique.

\section{EMD}

According to Huang et al. [9], EMD regards all signals as combinations of some linear or nonlinear inherent vibration modes, so all processed signals are decomposed into some IMFs. Each of the IMFs is subject to two criteria:

(1) Within the data series, the number of extreme points $N_{e}$ (including maximum points and minimum points) should be equal to the number of zero-crossing points $N_{z}$, or the difference between $N_{e}$ and $N_{z}$ should be no greater than 1:

$$
\left(N_{z}-1\right) \leq N_{e} \leq\left(N_{z}+1\right)
$$

(2) For any point $t_{i}$ within a time interval $\left[t_{a}, t_{b}\right]$, the absolute value of the upper envelope determined by local maximum points $f_{\max }(t)$ should be equal to that of the lower envelope determined by local minimum points $f_{\min }(t)$ :

$$
\frac{\left[f_{\max }\left(t_{i}\right)+f_{\min }\left(t_{i}\right)\right]}{2}=0, \quad t_{i} \in\left[t_{a}, t_{b}\right] .
$$

The first criterion guarantees that the IMFs represent traditional stationary processes. The second criterion turns the traditional global limits into the innovative local limits, which avoids the instantaneous fluctuations of the frequency caused by asymmetric waves. For any IMF fulfilling the two criteria, there exists only one extreme point between two neighboring zero-crossing points, and there are no complicated superimposed waves. A point that deserves our attention is that IMFs do not necessarily have to be narrowband signals, and they can be stationary signals with some band widths. Each IMF is defined and distinguished by the time delay between neighboring extreme values, and the decomposition of the original signal is accomplished progressively through a procedure named "sifting." Through "sifting," the original signal $f(t)$ can be expressed as the sum of $n$ IMFs $\left(c_{j}(t), j=1\right.$ to $\left.n\right)$ and a residue $\left(r_{n}(t)\right)$ :

$$
f(t)=\sum_{j=1}^{n} c_{j}(t)+r_{n}(t) .
$$

\section{Overview of Tests}

3.1. Field Measurement. Field measurements for windinduced pressures are conducted on a 167-m high large cooling tower located in Peng-cheng electric power plant in Xuzhou, China. The tower is surrounded by some typical electrical power plant buildings. There is a neighboring tower to its south with a distance of 1.5 times tower base diameter, and there is a large building complex to its west (see Figure 1).

During its construction, 36 pressure transducers were uniformly mounted around the tower's throat section at 


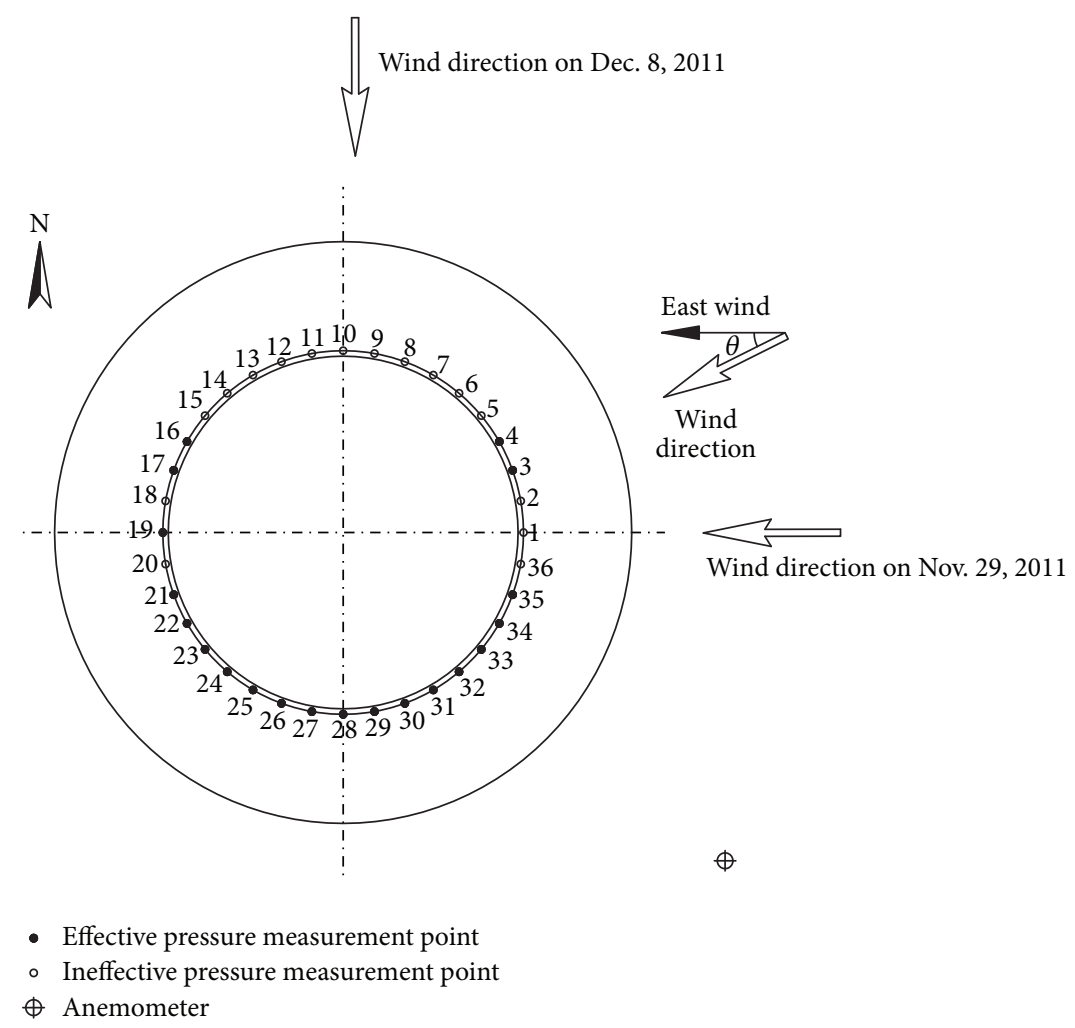

Figure 2: Plan of pressure measurement points.

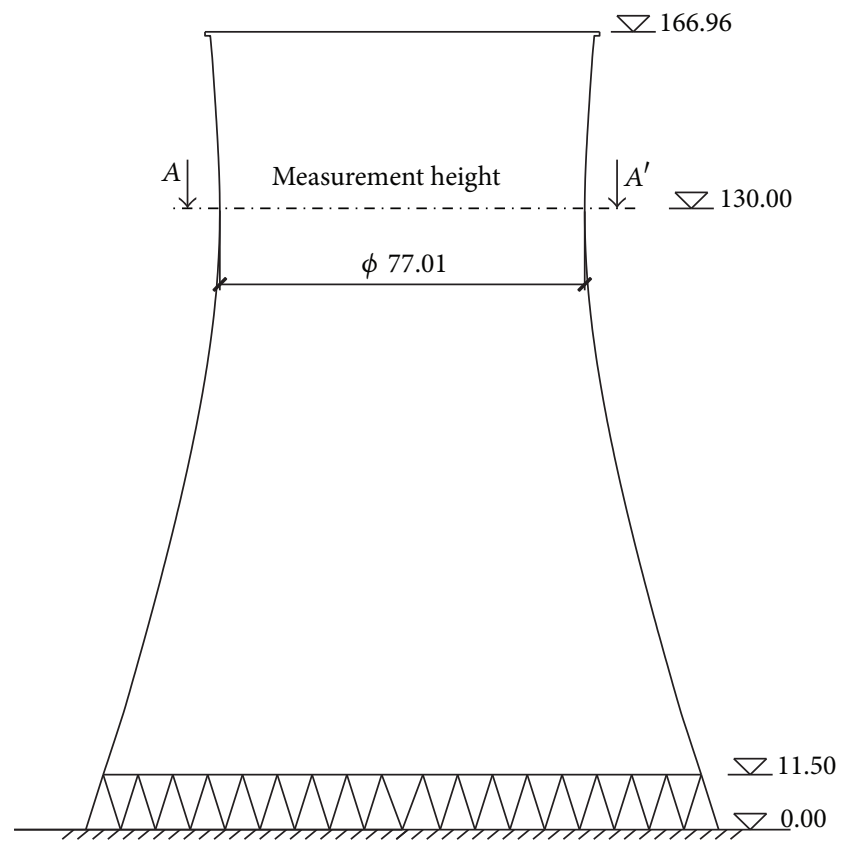

FIGURE 3: Projection of measuring tower (unit: m).

the height of $130 \mathrm{~m}$ (see Figures 2 and 3). Besides, another transducer is placed inside a cabin, which provides static reference pressure for measurements presented in this article.

The wind pressure transducers are piezoresistive ones (see Figure 4) whose maximum measured value is $\pm 2.5 \mathrm{kPa}$. Their

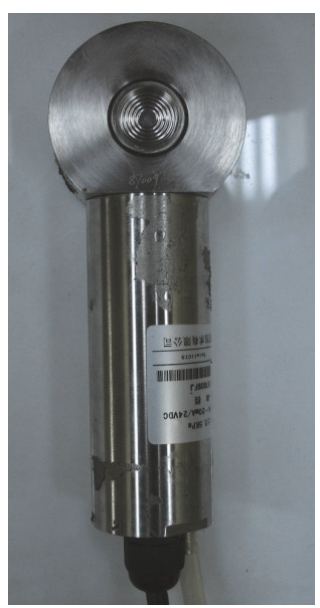

(a) Shape

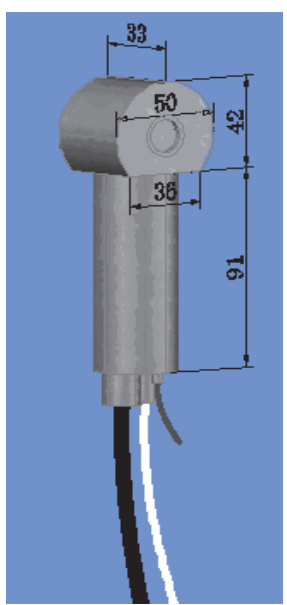

(b) Dimension (unit: $\mathrm{mm}$ )
FIGURE 4: Wind pressure transducer.

maximum sample frequency and precision are $100 \mathrm{~Hz}$ and 1/1000 maximum range, respectively. Before being installed on the prototype tower, the transducer is tested in a wind tunnel for its static and dynamic performances. It is found that when wind speed is greater than $11 \mathrm{~m} / \mathrm{s}$, the noise-to-signal ratio (i.e., the RMS of wind pressure divided by the mean wind pressure) is kept below 10\% (see Figure 5(a)). Besides, the signal produced by the transducer agrees with those obtained using high-precision electronic pressure scanivalve 


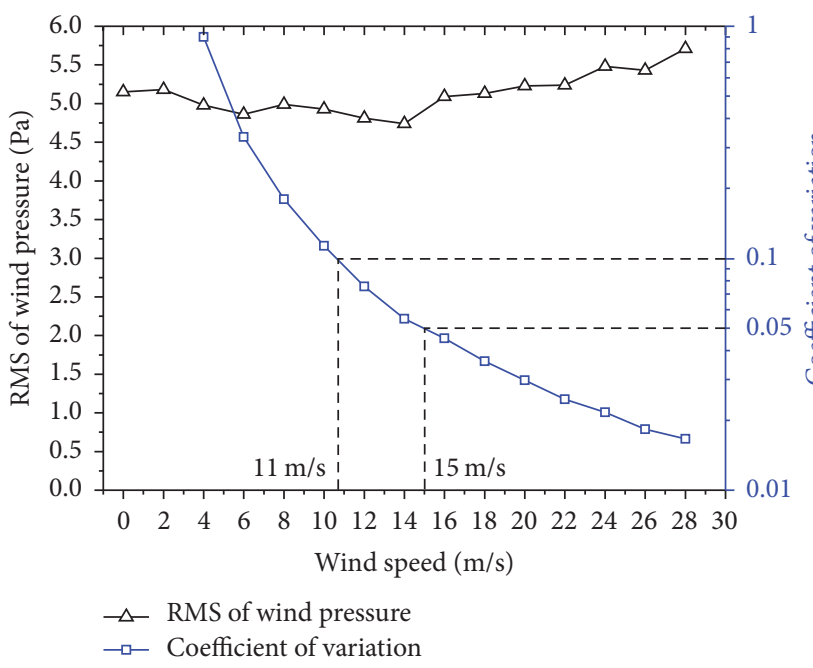

(a) Static performance

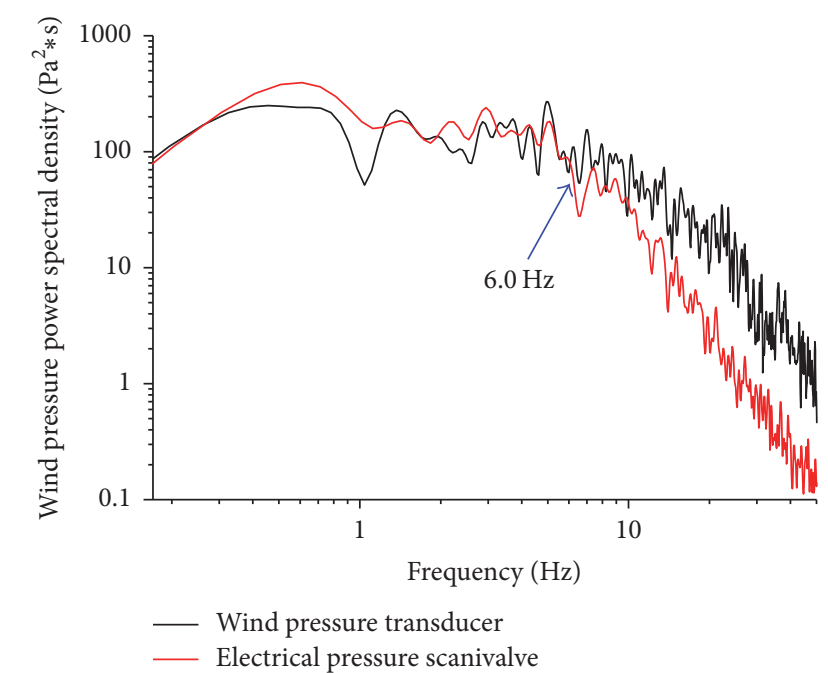

(b) Dynamic performance

FIGURE 5: Wind tunnel tests for transducer's performances.

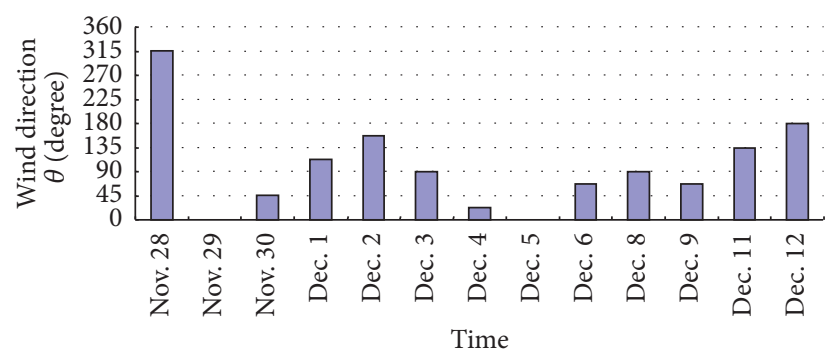

FIgURE 6: Predominant wind direction (see Figure 2 for definition of wind direction).

in $0-6 \mathrm{~Hz}$ frequency domain (see Figure 6(b)). These prove that both static and dynamic performances of the transducer are good.

Wind speed and direction are recorded by a $2 \mathrm{D}$ propeller anemometer and a 3D ultrasonic anemometer located to the southeast of the measuring tower at 20-m height (see Figure 2 for anemometers' position in plan). The whole measurement campaign lasts from 2010 to 2015 on 2-3 times of all-weather tests per year basis. In the huge amount of data measured, those obtained from Nov. 29, 2011, to Dec. 8, 2011, are found to be most representative. The daily predominant wind direction and the daily 10 -min mean wind velocity at measurement height obtained during that time are shown in Figures 6 and 7, respectively. The mean wind velocities are obtained at 20-m height and converted to the values at 130 $\mathrm{m}$ height using the power law formula of mean wind velocity profile whose exponent is chosen to be 0.16 according to [10].

According to [10], it is of interest to estimate the extent to which the effect of thermal convection is significant in structural engineering. The following expression should be used:

$$
U(z)=\frac{u_{*}}{k}\left[\ln \frac{z}{z_{0}}-\psi\left(\frac{z}{L}\right)\right]
$$

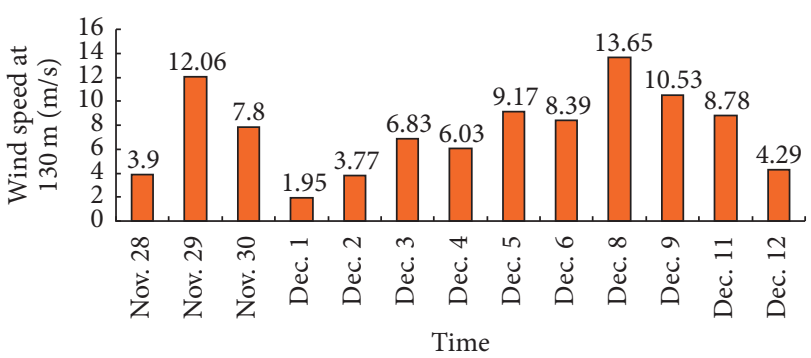

FIgURE 7: Calculated 10-min mean wind speed at measurement height.

where $U(z)$ is the mean wind speed at height $z$ considering thermal convection effect, $u_{*}$ is friction velocity, $k$ is von Karman's constant, $z_{0}$ is roughness length which is assumed to be $0.03 \mathrm{~m}$ for open terrain, and $\psi$ is Monin-Obukhov function, for which the following expression should be used in unstable air:

$$
\psi\left(\frac{z}{L}\right)=\int_{z_{0} / L}^{z / L}\left[1-(1-16 \zeta)^{-1 / 4}\right] \frac{d \zeta}{\zeta} .
$$

$L$ is Monin-Obukhov length, which is defined by the following expression:

$$
L=-\frac{u_{*}^{3}}{k(g / T)\left(Q_{0} / c_{p} \rho\right)},
$$

where $g$ is acceleration of gravity, $T$ is absolute temperature, $c_{p}$ is specific heat at constant pressure, $\rho$ is air density, and $Q_{0}$ is eddy heat flux.

It is a reasonable practice to take into account the dependence of the mean speed profile on temperature in calculating the 10-min mean wind speed at measurement height. In our case, the daily temperature is fortunately measured along with the wind environment information in 
TABLE 1: Mean wind speed updating for thermal convection effect.

\begin{tabular}{|c|c|c|c|c|c|c|c|}
\hline Date & Nov. 28 & Nov. 29 & Nov. 30 & Dec. 1 & Dec. 2 & Dec. 3 & Dec. 4 \\
\hline$u_{*} / \mathrm{m} / \mathrm{s}$ (calculated using the logarithmic law formula) & 0.19 & 0.58 & 0.37 & 0.09 & 0.18 & 0.33 & 0.29 \\
\hline$T / K$ (measured in the field) & 285.15 & Unknown & 279.15 & Unknown & Unknown & Unknown & Unknown \\
\hline$L / \mathrm{m}$ & -3.87 & - & -30.27 & - & - & - & - \\
\hline$\psi$ & 3.4383 & - & 1.964 & - & - & - & - \\
\hline$U(130 \mathrm{~m}) / \mathrm{m} / \mathrm{s}$ & 2.30 & - & 5.97 & - & - & - & - \\
\hline Date & Dec. 5 & Dec. 6 & Dec. 8 & Dec. 9 & Dec. 11 & Dec. 12 & \\
\hline$u_{*} / \mathrm{m} / \mathrm{s}$ & 0.44 & 0.40 & 0.65 & 0.50 & 0.42 & 0.20 & \\
\hline$T / \mathrm{K}$ & 282.15 & 281.65 & 277.15 & 276.65 & 280.65 & 278.15 & \\
\hline$L / \mathrm{m}$ & -49.72 & -38.02 & -161.09 & -73.82 & -43.41 & -5.02 & \\
\hline$\psi$ & 1.652 & 1.8182 & 1.0094 & 1.4197 & 1.7352 & 3.2399 & \\
\hline$U(130 \mathrm{~m}) / \mathrm{m} / \mathrm{s}$ & 7.36 & 6.57 & 12.00 & 8.74 & 6.96 & 2.63 & \\
\hline
\end{tabular}

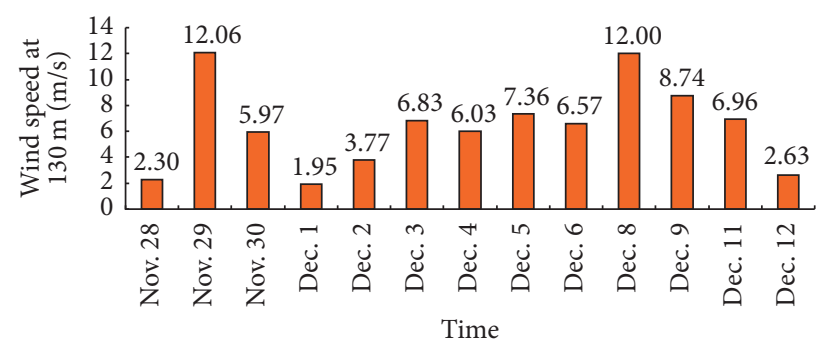

FIGURE 8: Updated 10-min mean wind speed at measurement height considering thermal convection effect.

most of the days. Thus, the calculated 10-min mean wind speeds presented in Figure 7 can be updated using (4)-(6) for thermal convection effect. The updated results are presented in Table 1 and Figure 8.

As can be seen from Figure 8, only wind speeds for Nov. 29,2011 , and Dec. 8, 2011, exceed $12 \mathrm{~m} / \mathrm{s}$, which represent valid strong wind scenarios. However, the wind directions on the two days are quite different. On Nov. 29, 2011, the oncoming flow is from due east, but it is from due north on Dec. 8, 2011 (see Figure 6). Although 36 transducers were installed around the full-circle, some of them on the tower's north surface are unfortunately found to be ineffective (see Figure 2). So only data obtained on Nov. 29, 2011, are complete half-circle wind effects, which are utilized for this study.

3.2. Wind Tunnel Model Test. The full-scale scenario is also simulated in the TJ-3 wind tunnel of Tongji University in Shanghai, China. The wind tunnel is a closed circuit rectangular cross-section wind tunnel, wherein the size of the test section is $15 \mathrm{~m}$ in width, $2 \mathrm{~m}$ in height, and $14 \mathrm{~m}$ in length. The test wind speed can be continuously controlled in the 1.0 to $17.6 \mathrm{~m} / \mathrm{s}$ range. The nonuniformity of the wind speed of the flow field in the test zone is less than $1 \%$, the turbulence intensity is less than $0.5 \%$, and the average flow deviation angle is less than $0.5^{\circ}$. Using spires and ground roughness blocks (see Figure 9(a)), the ABL flow field of countryside open terrain according to $[10,11]$ is simulated for the test, as is shown by Figure 10. In Figure 10(a), the powerspectral density is measured at $1 \mathrm{~m}$ height, and the simulated turbulence integral scale at that height is around $0.3 \mathrm{~m}$. The test model and the surroundings are modeled on a geometric scale of 1:200 using synthetic glass (see Figure 9(b)).

$36 \times 12$ taps are arranged on 12 vertical sections and 36 horizontal circular directions for the pressure measuring tower model. DSM3000 electronic pressure scanners of Scanivalve Corp. are used to obtain the wind pressures on the tower surfaces. The signal data are acquired at a sample rate of $312.5 \mathrm{~Hz}$, and the sample length is 6000 pieces of data at one tap in each run. With the aid of sticking paper belts along the vertical direction and by adjusting the incoming flow velocity, the actual static characteristics of the prototype cooling tower at high Reynolds number (Re) are successfully simulated in the reduced-scale model with lower Re, which can be proved from a good fitting of mean wind pressure distributions at towers' throat sections based on the model test and the code [11], respectively (see Figure 11). The optimum simulation condition is a model with 36 one-layer ( $0.1 \mathrm{~mm}$ thickness) paper tapes and $10 \mathrm{~m} / \mathrm{s}$ wind speed. The turntable rotates from $0^{\circ}$ to $360^{\circ}$ at $22.5^{\circ}$ intervals, but only the case with the same wind direction as that observed in the field on Nov. 29, 2011, is considered (see Figure 2), so the wind effects obtained from the model test can compare with the full-scale results.

\section{Stationarity Tests}

The 10-min wind pressure time-history samples are produced by transducers arranged around the half-circle at the throat of Peng-cheng cooling tower. Some of them show nonstationarity as their mean components change over time. The wind pressure time-history samples produced by the transducers at 20 degrees and 140 degrees can be taken as examples. In Figure 12, the time-varying mean of the first curve for the wind pressure time-history sample produced by the transducer at 20 degrees fluctuates around 0.57 from 0 to $400 \mathrm{~s}$, and then it gradually drops to 0.5 from $400 \mathrm{~s}$ to $600 \mathrm{~s}$. Similar situation holds true for the wind pressure timehistory sample produced by the transducer at 140 degrees, as shown by the fourth curve in Figure 12. However, some other samples show stationary features as their mean components do not vary significantly over time, for example, the two samples produced by transducers at 80 degrees and 110 


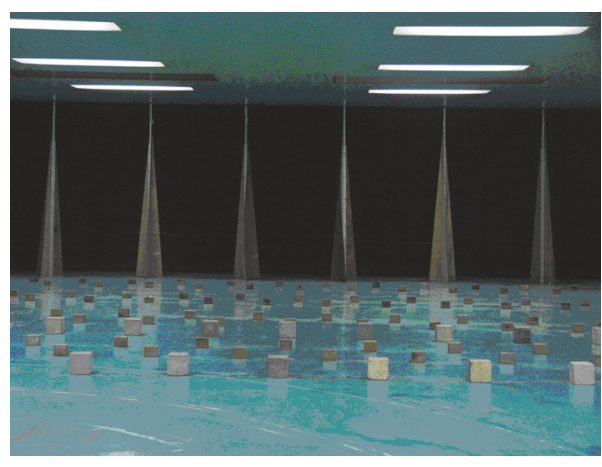

(a) Terrain simulation

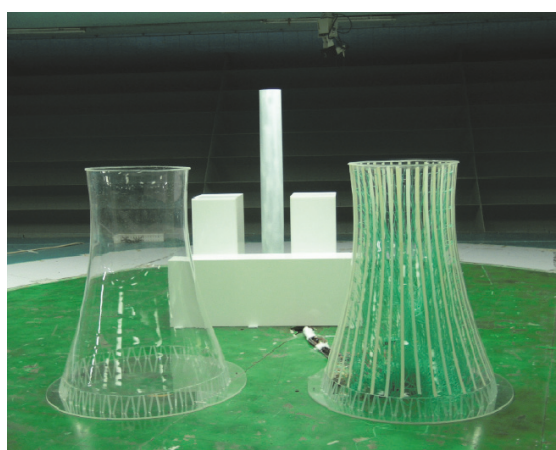

(b) 1:200 rigid models

FIGURE 9: Model test scenario in TJ-3 wind tunnel.

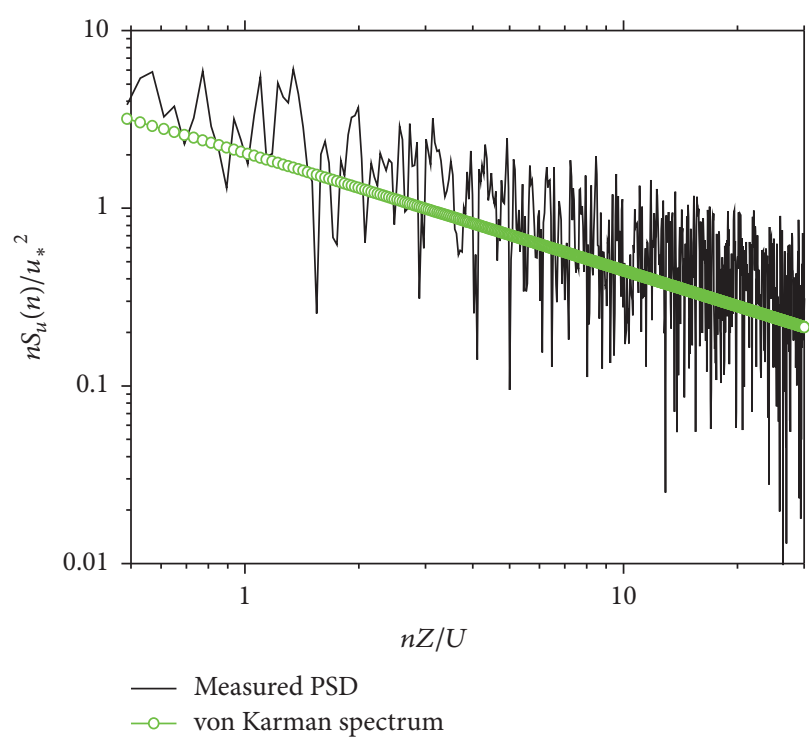

(a) Power-spectral function for along-wind component of wind speed

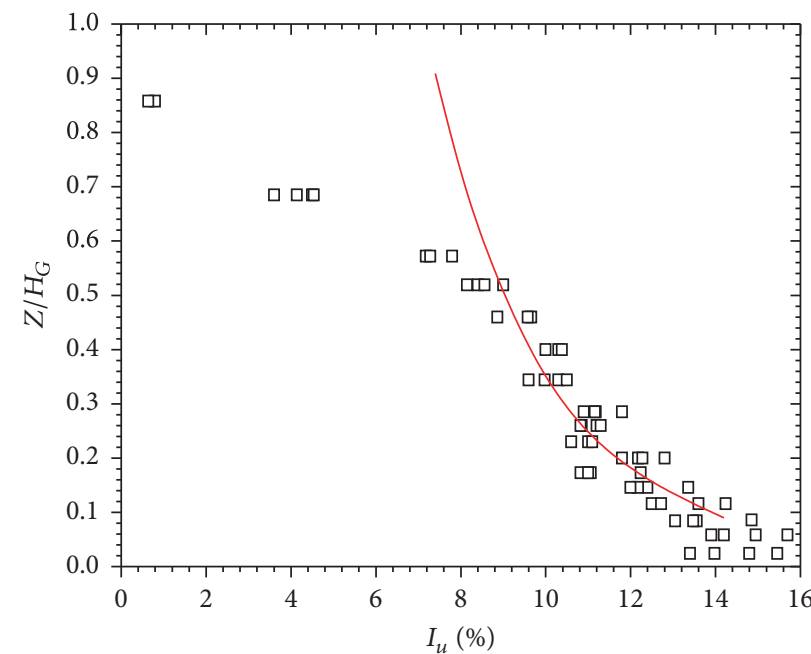

口 $\quad$ Measured value

- Theoretical profile

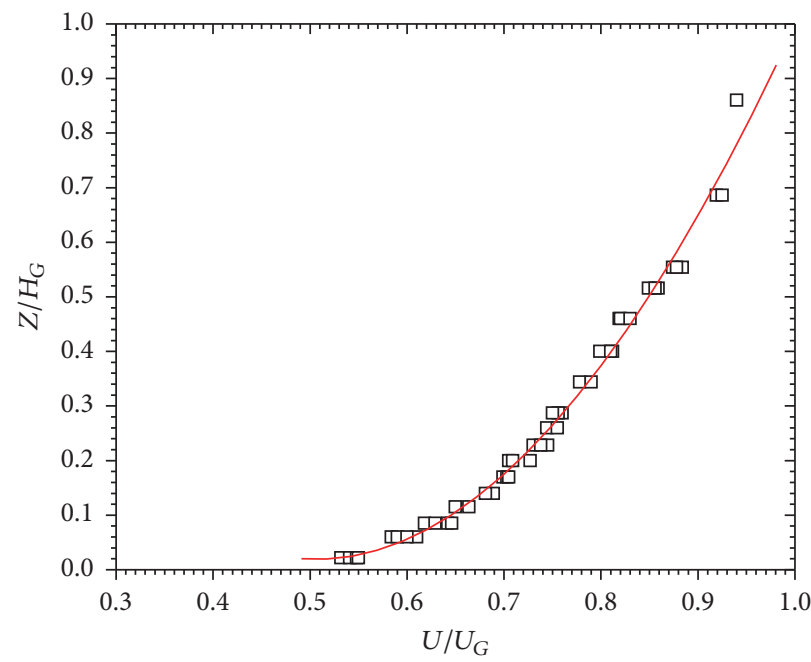

$\square \quad$ Measured value

- Theoretical profile $U / U_{G}=\left(Z / H_{G}\right)^{0.16}$

(c) Average wind velocity profile

FIGURE 10: ABL flow field simulated for countryside open terrain in TJ-3 $\left(H_{G}\right.$ and $U_{G}$ refer to the gradient height and the geostrophic velocity, resp.). 


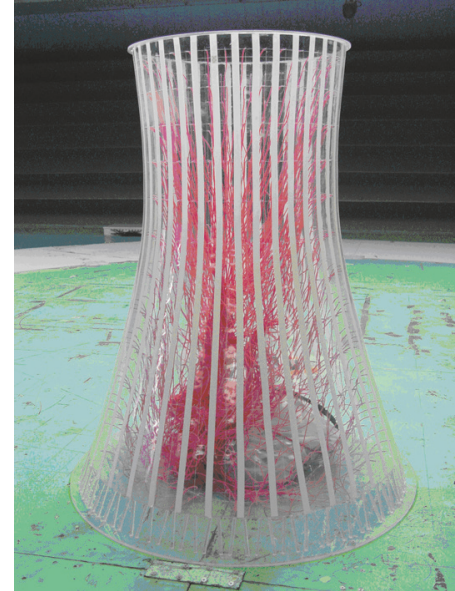

(a) Pressure measurement model with paper belts

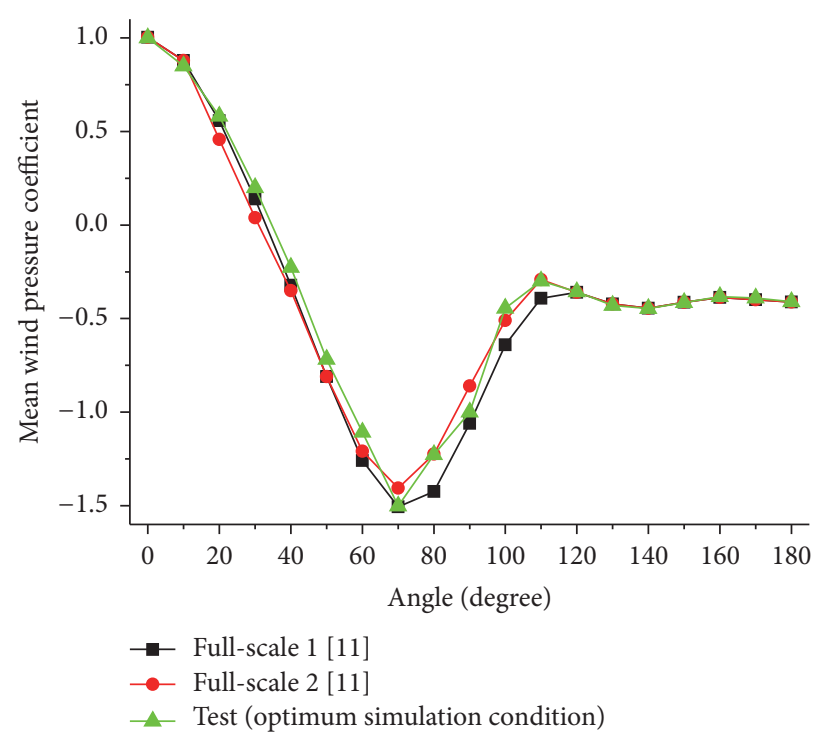

(b) Mean wind pressure distributions at towers' throat sections

Figure 11: Re-effect simulation for model test.

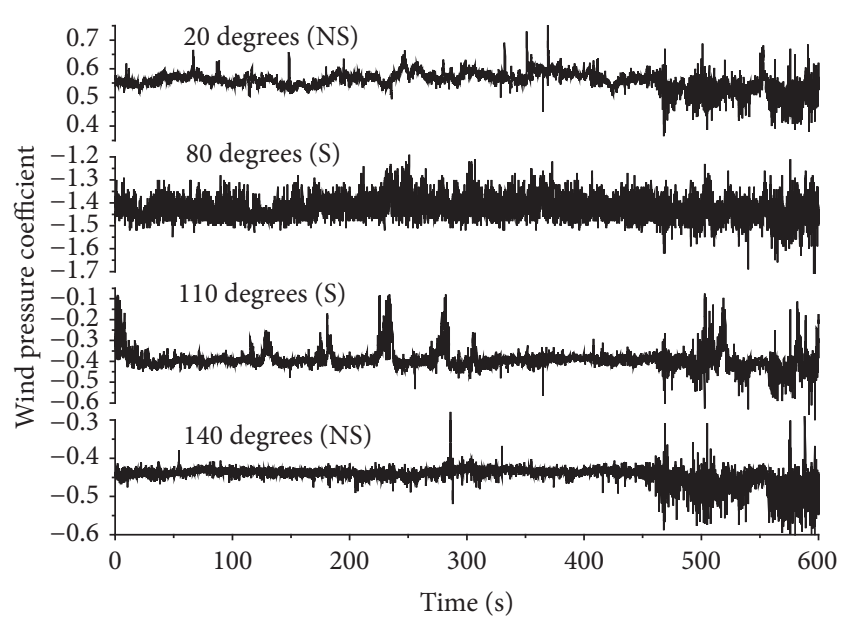

FIGURE 12: Time-history samples of wind pressure coefficients at four positions (the legend refers to the included angle between the position of transducer and stagnation point, and S and NS refer to stationary and nonstationary, resp.).

degrees (see the second curve and the third curve in Figure 12, resp.). For the third curve in Figure 12, some intermittent pulses can be observed which relate to the sample's nonGaussian feature. These preliminary judgments of samples' nonstationarity should be further verified.

The verifications of nonstationarity are performed on the full-scale wind pressure time-history samples produced by transducers at different positions using runs test. Each sample of 10-min duration is divided into 30 segments. As presented by Bendat and Piersol [12], runs test is to determine
TABLE 2: Stationarity test results for original full-scale samples.

\begin{tabular}{ll}
\hline Position & $\square$ \\
\hline 20 degrees & $\square$ \\
30 degrees & $\square$ \\
40 degrees & $\square$ \\
50 degrees & $\bullet$ \\
60 degrees & $\bullet$ \\
70 degrees & $\bullet$ \\
90 degrees & $\bullet$ \\
100 degrees & $\square$ \\
110 degrees & $\bullet$ \\
120 degrees & $\bullet$ \\
130 degrees & $\square$ \\
150 degrees & $\square$ \\
160 degrees & $\square$ \\
180 degrees & $\bullet$ \\
\hline
\end{tabular}

Note. Stationary; $\square$ : nonstationary.

samples' nonstationarity in terms of the mean-square value. Table 2 lists the results for all wind pressure samples with a significance level of 0.025 . It can be seen from Table 2 that $50 \%$ samples fail to pass the stationarity test which agrees with the finding from Figure 12, proving that the realistic wind effects often lack stationarity. Transducers that produce the nonstationary samples exist in both the windward region (from 20 to 50 degrees) and the wake region (from 120 to 140 degrees). 
TABLE 3: Stationarity test results for samples obtained from the model test.

\begin{tabular}{ll}
\hline Position & \\
\hline 0 degrees & degrees \\
20 degrees & \\
30 degrees & \\
40 degrees & degrees \\
60 degrees & $\bullet$ \\
70 degrees & $\bullet$ \\
80 degrees & $\bullet$ \\
90 degrees & $\bullet$ \\
100 degrees & $\bullet$ \\
120 degrees & $\bullet$ \\
130 degrees & $\bullet$ \\
140 degrees & $\bullet$ \\
150 degrees & $\bullet$ \\
170 degrees & $\bullet$ \\
180 degrees & $\bullet$ \\
\hline
\end{tabular}

Note. @: Stationary; $\square$ : nonstationary.

Furthermore, runs test is conducted in the same way to evaluate the nonstationarity of the samples obtained from the wind tunnel model test. In Table 3, 18 out of 19 samples are found to be stationary, suggesting that unrealistic stationary wind effects might be obtained on models in a traditional passively wind tunnel.

\section{Data Processing Using EMD}

Full-scale wind pressure samples that fail to pass the stationarity test are processed using EMD, and the results for the sample produced by transducer located at 20 degrees are shown in Figure 13. The first curve displayed in Figure 13 is the original wind pressure time-history sample. After applying EMD to the original wind pressure time-history sample, a total of 12 IMF components (curves IMFs 1 12) and one final residue are obtained and shown in Figure 13. As can be seen, the IMF components start from the highest and end at the lowest frequency in sequence. The final residue can be regarded as the time-varying mean wind pressure, as tend of the original sample is the final residue [9]. According to $\mathrm{Xu}$ and Chen [6], the sample's failure to pass the stationarity test is attributed to the existence of such a residue.

For the full-scale samples failing to pass the stationarity test, the final residue is replaced by the constant mean wind pressure to form new samples. Runs test is then applied to each new sample with the same number of data segments and significance level as used in the runs test for the original full-scale data. The results listed in Table 4 show that none of them pass the stationarity test. A further step is taken to subtract some IMFs of low frequencies from the nonstationary samples. It has been found that, with a few IMFs subtracted, some samples can pass the stationarity test. As shown in Table 4, when the residue is replaced by the constant mean and 6 12 IMFs are all subtracted, 6 out of 8 samples can pass the stationarity test. This indicates that the nonstationarity of samples might be induced not only by the residue, but also by some IMFs of low frequencies. In Table 4, 2 samples still fail to pass stationarity test after the residue is replaced by the constant mean and $6 \sim 12$ IMFs are all subtracted. Their nonstationarity might relate to the nonstationary fluctuations, rather than the time-varying mean components.

\section{Loading Characteristics Extracted from Stationary and Nonstationary Samples}

In this portion of study, wind loading characteristics are extracted from the original full-scale wind pressure timehistory samples, the processed full-scale samples (the original nonstationary samples with the residue replaced by the constant mean and 6 12 IMFs subtracted), and the model test samples, respectively. Then they are compared with each other to demonstrate the effects of nonstationarity and to evaluate the accuracy of the wind tunnel model test.

6.1. Mean/Fluctuating Wind Pressure Distributions. The mean wind pressure distributions produced using different data are shown in Figure 14. As can be seen, the original full-scale pattern completely overlaps the processed full-scale distribution, indicating that the mean wind pressure coefficients have not been changed by removing the original full-scale sample's nonstationarity. Besides, the model test result is close to the two full-scale curves. This suggests that although similarity problems exist, the wind tunnel simulation technique is reliable in simulating the static wind effects on structures.

Different from Ruscheweyh [13], the full-scale fluctuating wind pressure distributions in Figure 15 are not fitted curves with the smoothing treatment, so they show some oscillations. A comparison between the original full-scale curve and the processed full-scale curve suggests that the sample's nonstationarity exerts a significant influence on the fluctuating wind pressure coefficient. When the nonstationarity is removed from the samples in windward and wake regions, the values of the full-scale fluctuating wind pressure coefficient are greatly reduced. Besides, the model test curve is different from the original full-scale curve, but it is close to the processed full-scale result. This suggests that the deficiency of the wind tunnel technique in simulating nonstationarity causes some inaccuracies to the results. However, if this problem is solved, the wind tunnel simulation technique can be satisfactory.

6.2. Power-Spectral Densities. Figure 16 shows the powerspectral densities for wind pressure coefficient fluctuations at different positions. As can be seen, the power-spectral densities for the processed full-scale samples are generally lower than those for the original full-scale samples in the low frequency ranges, since the low frequency components have been removed from the original samples. However, 


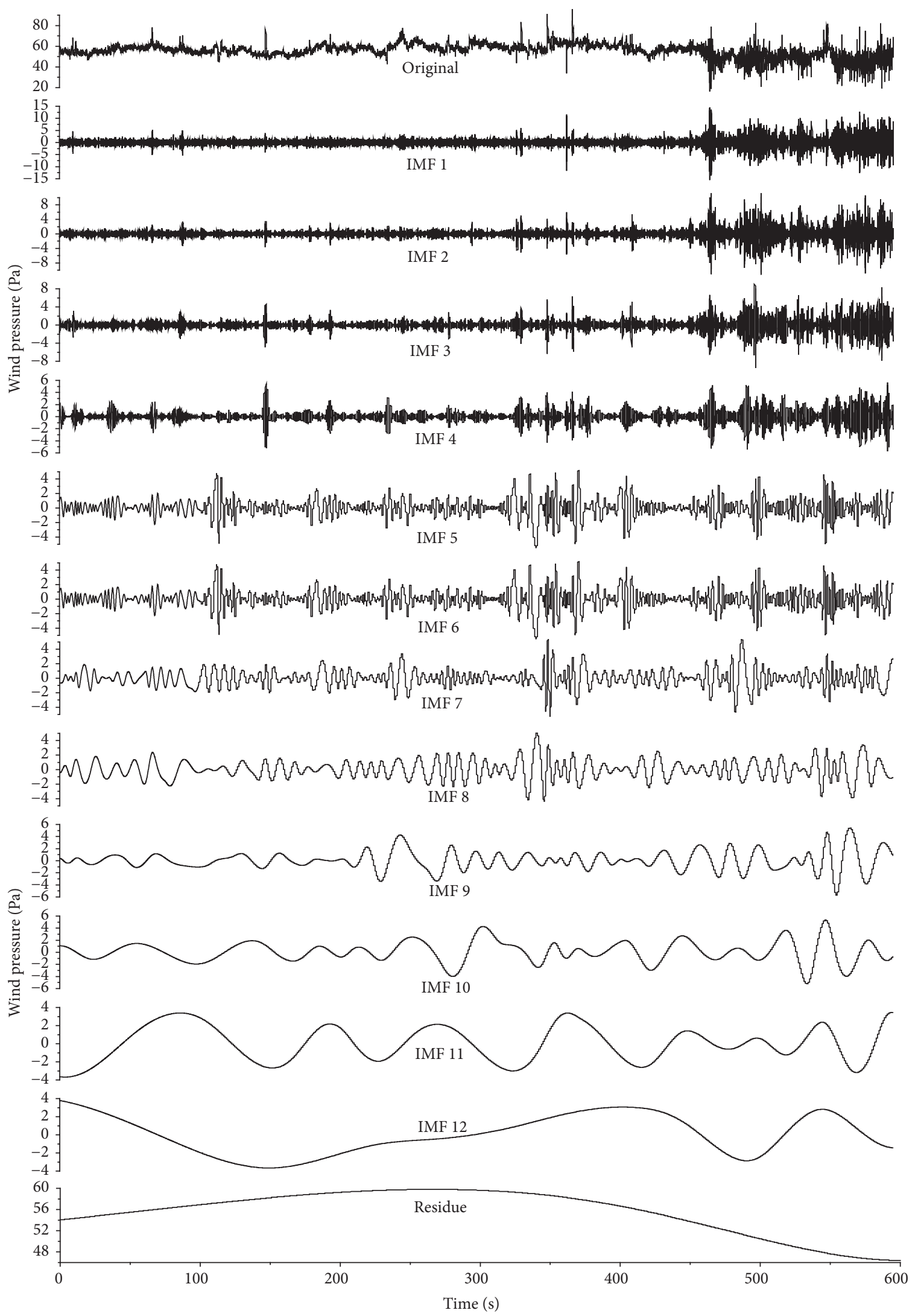

FIGURE 13: EMD decompositions of the sample produced by the transducers at 20 degrees. 
TABLE 4: Stationarity test results for processed full-scale samples.

Position

Case 1: Replacing residue by constant mean

20 degrees

30 degrees

40 degrees

50 degrees

100 degrees

120 degrees

130 degrees

140 degrees

Case 2: Replacing residue by constant mean and subtracting IMFs $6 \sim 12$

20 degrees

30 degrees

40 degrees

50 degrees

100 degrees

120 degrees

130 degrees

140 degrees

Note. : Stationary; $\square:$ nonstationary.

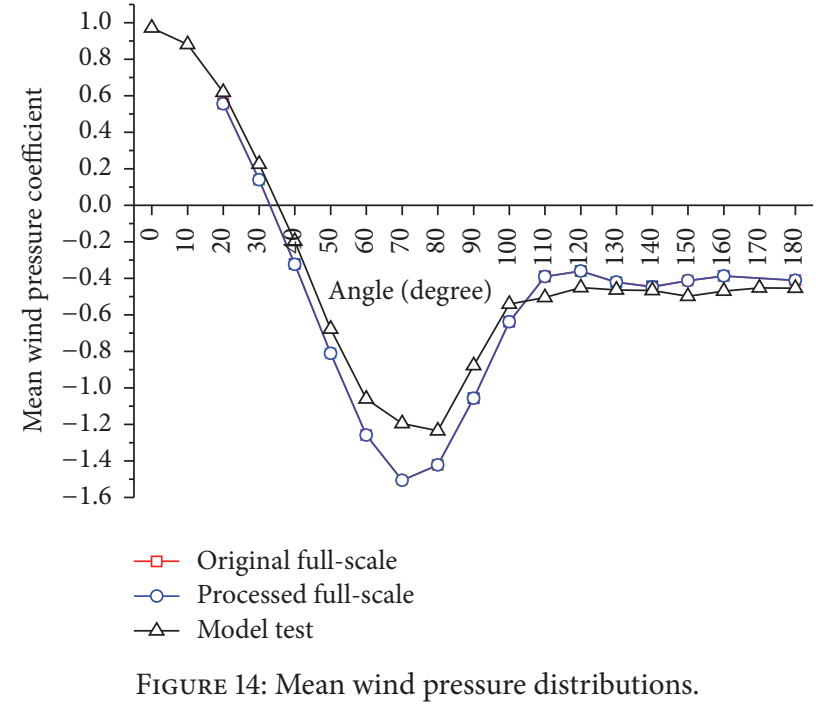

the power-spectral densities in high frequency ranges for the processed full-scale samples are higher. This is because the power-spectral densities are divided by the variance of the sample to produce the nondimensional values shown in Figure 16, and the variances are greater for the original samples than for the processed samples. In reality, the powerspectral densities of the two full-scale samples are supposed to be the same in high frequency ranges.

Besides, the model test values are close to the original full-scale values in low frequency ranges, but they are a little

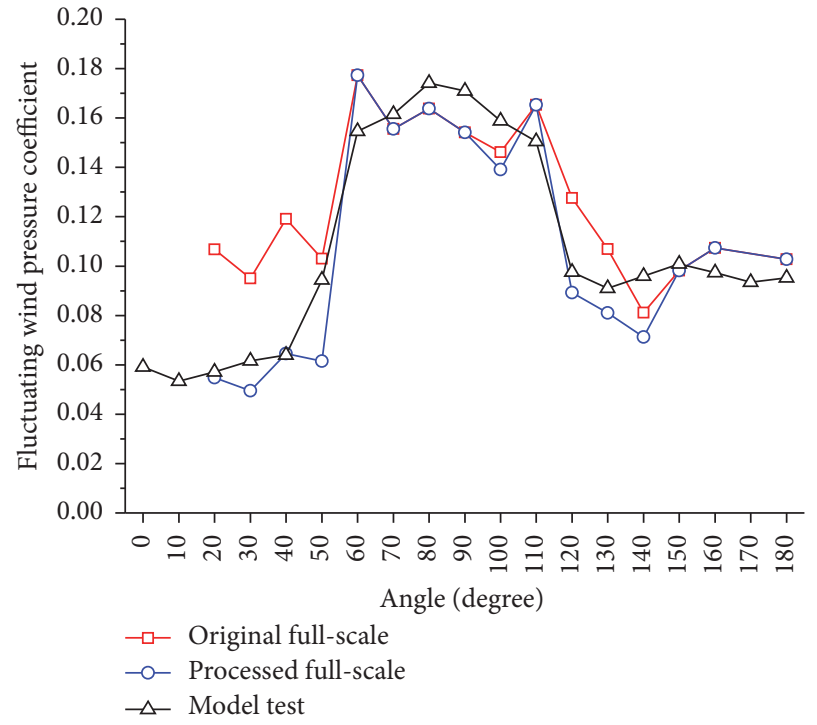

FIGURE 15: Fluctuating wind pressure distributions.

higher than the original full-scale values in high frequency ranges. This suggests that the wind tunnel simulation technique is relatively accurate with respect to the power-spectral densities.

6.3. Coherence Functions. Coherence functions between wind pressure coefficient fluctuations at 20 degrees and those at other positions are shown in Figure 17. As shown in Figures $17(a)-17(d)$, the original full-scale coherence for two samples 


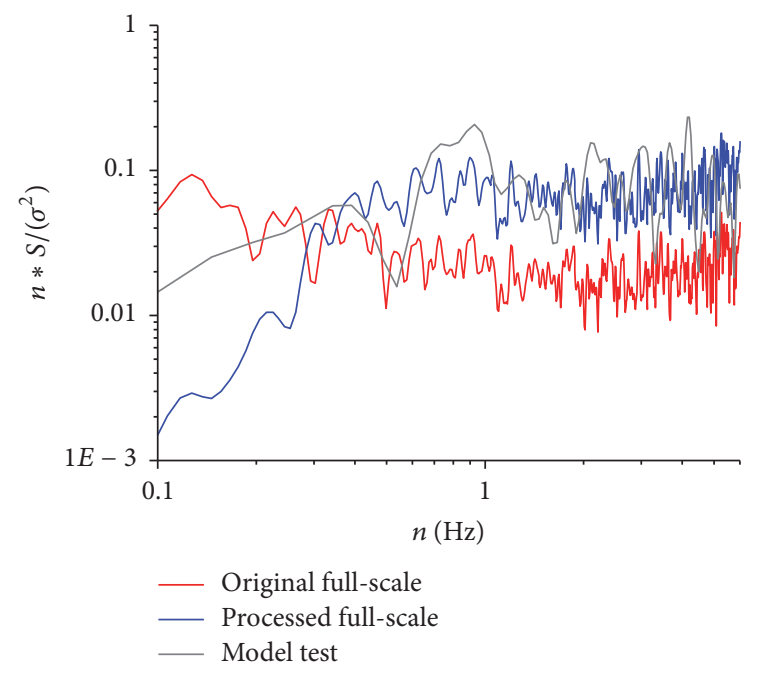

(a) 20 degrees

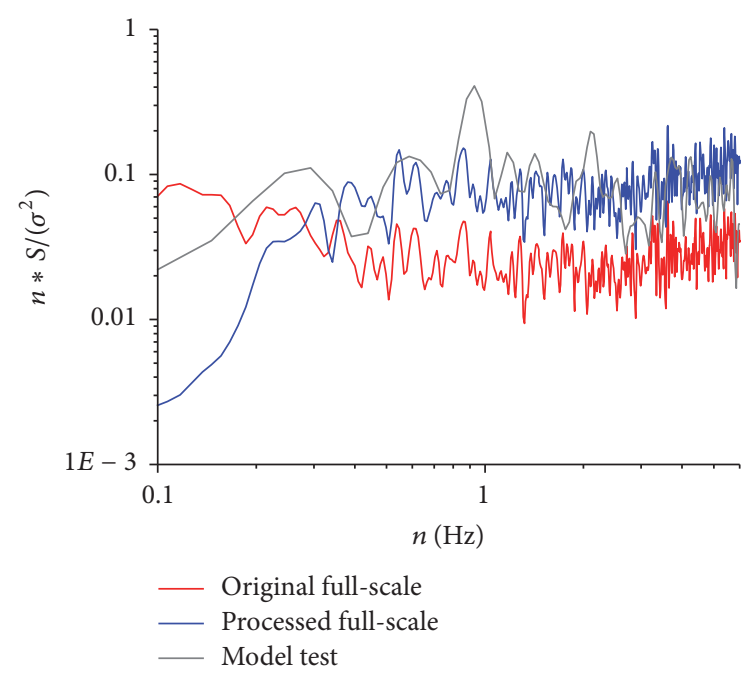

(c) 40 degrees

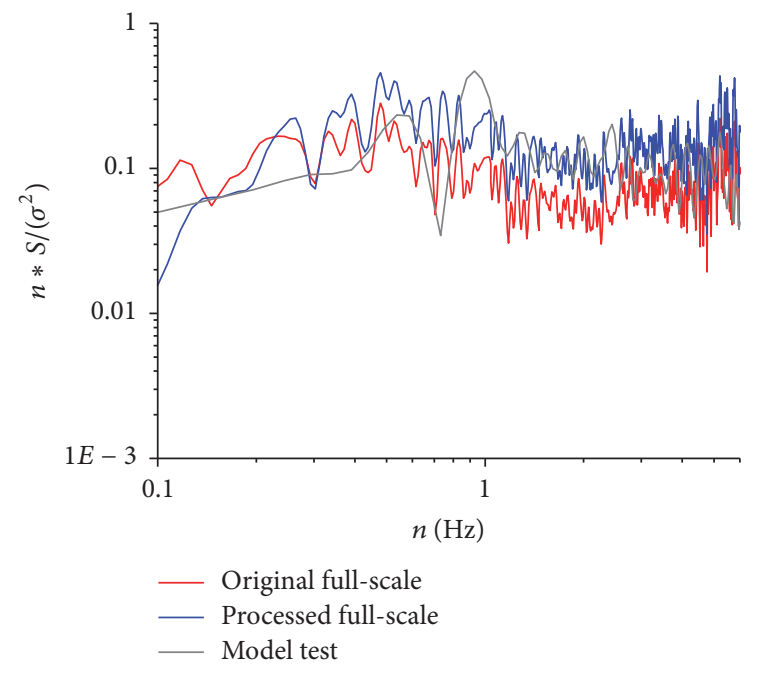

(e) 120 degrees

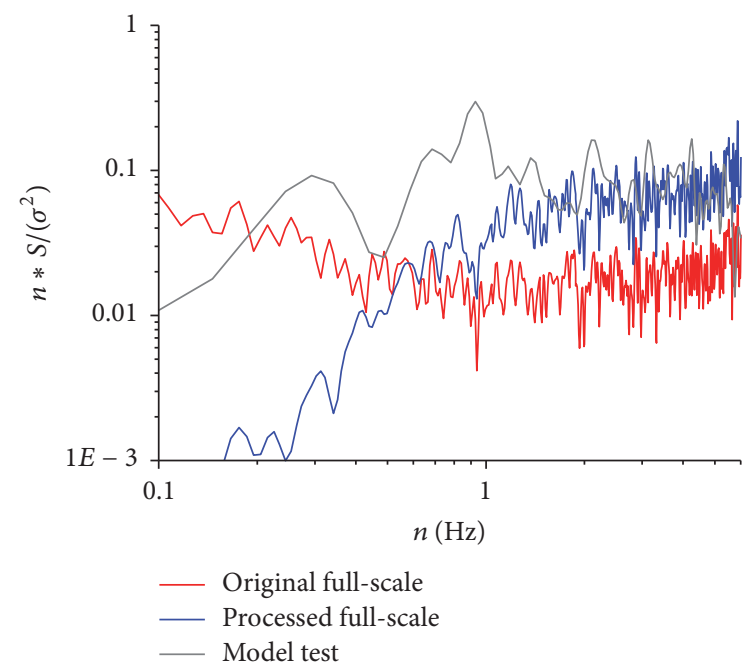

(b) 30 degrees

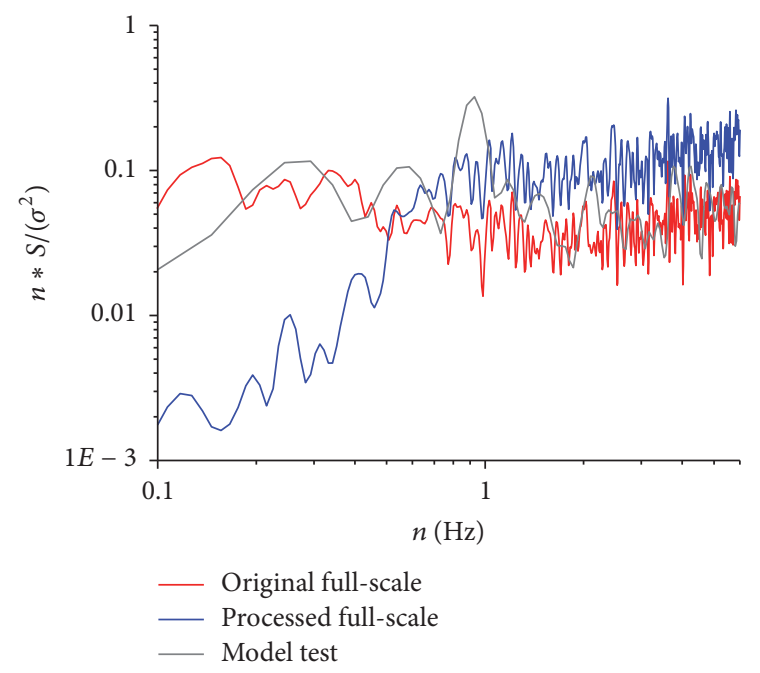

(d) 50 degrees

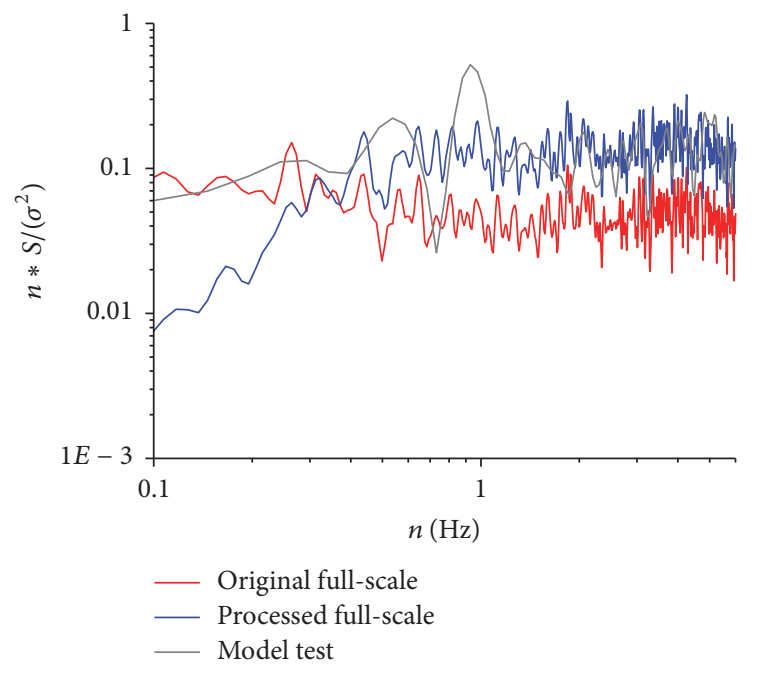

(f) 130 degrees

FIgURE 16: Power-spectral densities. 


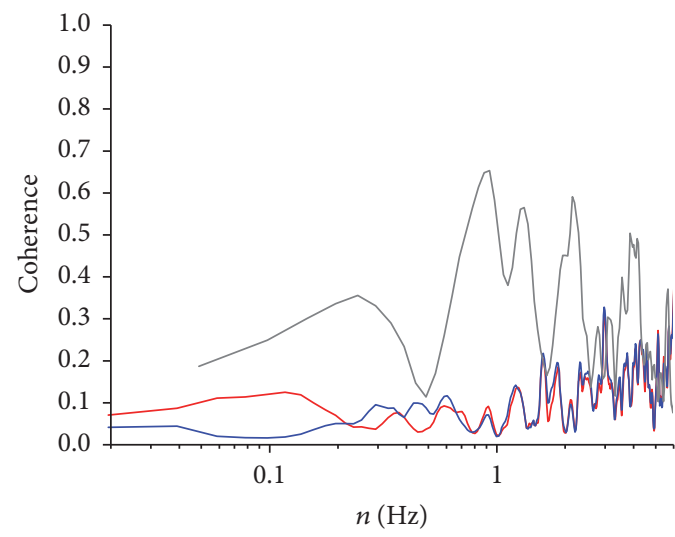

Original full-scale

Processed full-scale

— Model test

(a) 20 degrees-40 degrees

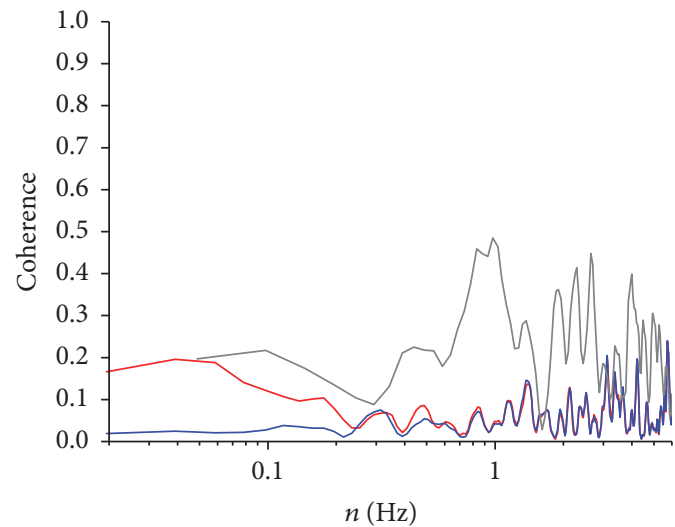

_ Original full-scale

_ Processed full-scale

— Model test

(c) 20 degrees-70 degrees

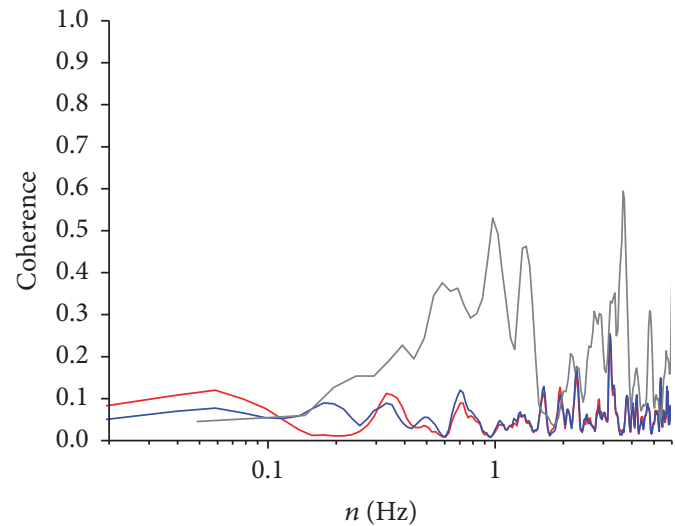

- Original full-scale

Processed full-scale

- Model test

(e) 20 degrees-110 degrees

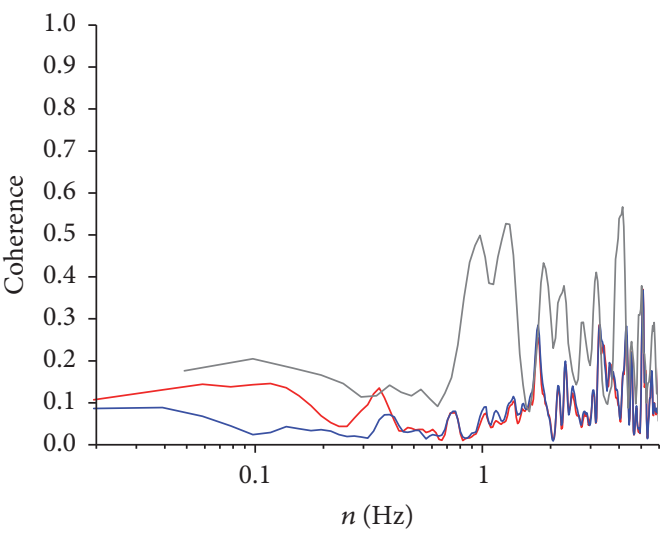

Original full-scale

Processed full-scale

— Model test

(b) 20 degrees-50 degrees

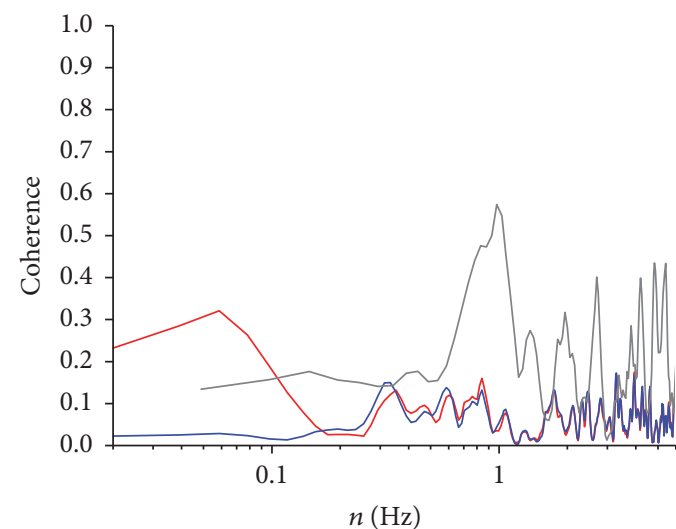

- Original full-scale

_ Processed full-scale

— Model test

(d) 20 degrees-90 degrees

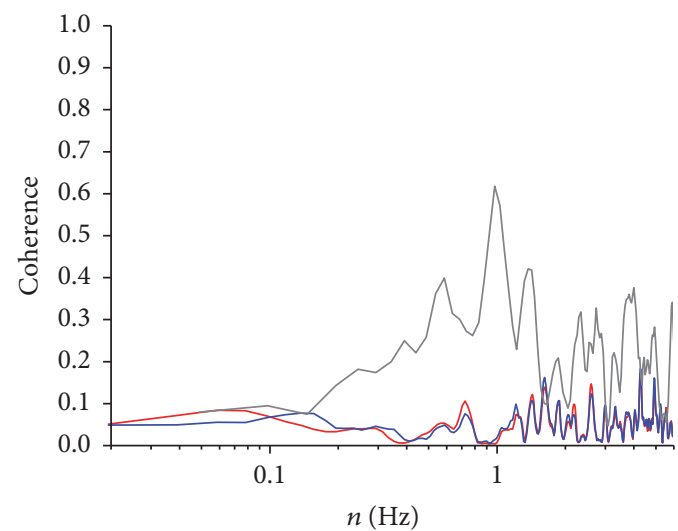

Original full-scale

Processed full-scale

Model test

(f) 20 degrees-120 degrees

FIGURE 17: Coherence functions between the wind pressure coefficient fluctuation at 20 degrees and those at other positions. 
within the region 0-90 degrees is higher than the processed full-scale coherence in the low frequency range, but the two full-scale curves completely overlap in the frequency range $0.6-6 \mathrm{~Hz}$. This indicates that the low frequency components that induce the sample's nonstationarity are closely correlated at windward side. However, both the original full-scale and the processed full-scale coherence between samples at the windward side (20 degree) and the leeward side (90-180 degree) are very poor over the full frequency domain, as is shown in Figures 17(e) and 17(f). This further suggests that the nonstationarity of samples has little effects on the coherence function when wind pressures are produced by two transducers located far away.

Besides, the model test coherence is notably stronger than the full-scale coherence in all cases in Figure 17. On the other hand, the power-spectral densities obtained from the model test are found to be relatively accurate according to Section 6.2. Thus, conservative results might be obtained if the model test cross-spectral densities are used for structural dynamic response analyses.

6.4. Probability Density Functions. Probability density functions for wind pressure coefficient fluctuations obtained in the wind tunnel have been studied by Ke and Ge [14]. It has been found that the zone from the windward point to the negative extreme value point (1st zone) is Gaussian distribution zone, the zone from the negative extreme value point to the separation point (2nd zone) is non-Gaussian distribution zone which is caused by the organized large vortices formed nearby, and the zone from the separation point to the protected area (3rd zone) is featured with Gaussian distribution. However, Cheng et al. [3] found by field measurements that probability density functions for wind pressure coefficient fluctuations obtained in the 1st and the 3rd zones also feature non-Gaussian distributions and suggested that the nonstationary wind velocity and the unsteady wind direction in the realistic engineering field are an explanation for the phenomenon.

The probability density functions for both the original full-scale samples obtained in the 1st and the 3rd zones and the corresponding processed full-scale samples are shown in Figure 18. As can be seen, almost all the original fullscale distributions deviate far from the Gaussian distribution. However, when the nonstationarity is removed from the original samples, the processed samples approach the Gaussian distribution. This proves that the nonstationarity should be responsible for the non-Gaussian distributions observed by field measurements in the 1st and the 3rd zones. This finding is supported by $\mathrm{Xu}$ and Chen [6].

6.5. Spatial Correlations. The correlation coefficients between full-scale samples produced by transducers at 20, 80, 140 degrees and those produced by other transducers are shown in Figure 19. As can be seen, the basic curve patterns for the original full-scale correlation agree well with those for the processed full-scale correlation. However, when the nonstationarity is removed from the samples, the spatial correlations are weakened. This suggests that the nonstationarity can strengthen the correlation between pressures at different positions.

\section{Conclusions}

Using runs test, some wind pressure time-history samples measured on the throat section of a full-scale $167-\mathrm{m}$ high cooling tower are found to be nonstationary. Most of them are in the windward region and the wake region. As a promising tool for analyzing wind effects on structures, EMD has been applied to those nonstationary samples. It is found that both the residue and some IMFs of low frequencies produced by EMD are responsible for the samples' nonstationarity. Replacing the residue by the constant mean and subtracting some IMFs of low frequencies can help the samples pass the runs test.

Comparisons have been made between the loading characteristics extracted from the original nonstationary samples and those extracted from the processed stationary samples. It is found that when the original sample's components responsible for nonstationarity are replaced or subtracted, the fluctuating wind pressure coefficient and the power-spectral density in low frequency range are generally reduced, and the coherence in low frequency range and the spatial correlation between wind pressures obtained at different positions are usually weakened. Only when wind pressures are produced by two transducers located far away, the nonstationarity effects on the coherence function are insignificant. For the probability density function, previous studies indicated that the results obtained from the model test and those from the field measurement are quite different in 1st and 3rd zones. This paper proves that the discrepancy of stationarity should be responsible for that difference. With nonstationarity removed from the full-scale nonstationary sample, the probability density function could be changed from a nonGaussian distribution to an approximate Gaussian pattern. In sum, these observations suggest that nonstationarity effects on wind loads are generally notable and the attempts to quantify wind effects on structures for either wind-engineering design or research require appropriate consideration of their realistic nonstationary features.

Besides, the wind effects obtained in the wind tunnel are compared with the full-scale results to examine the accuracy of the traditional passive wind tunnel simulation technique. It has been found that the technique is basically conservative in use, although it is based on the assumption of stationarity. However, if advanced simulation techniques are employed, for example, using the actively controlled wind tunnel to simulate realistic nonstationary wind velocity fields, the model test results obtained could be more reliable.

\section{Conflicts of Interest}

The authors declare that there are no conflicts of interest regarding the publication of this article. 


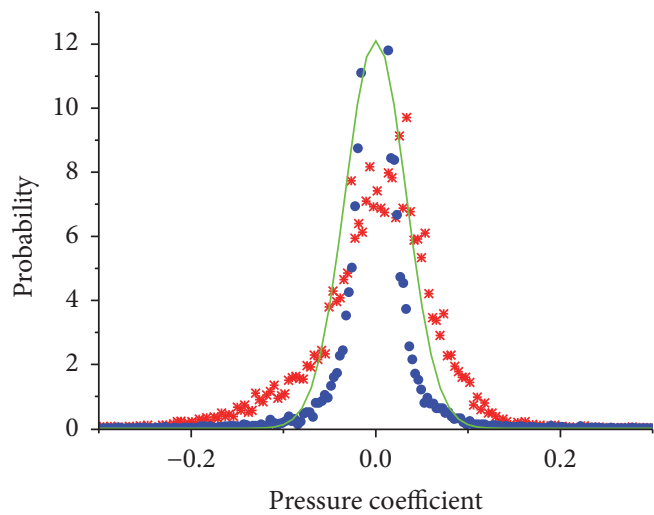

* Original full-scale

- Processed full-scale

- Gaussian distribution

(a) 20 degrees

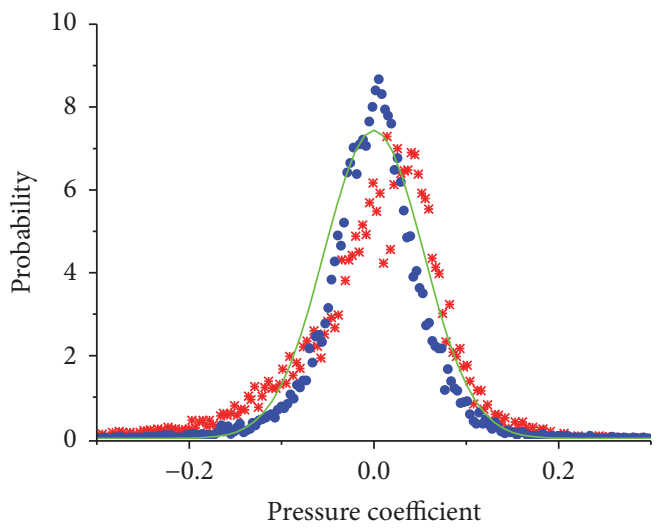

* Original full-scale

- Processed full-scale

_ Gaussian distribution

(c) 120 degrees

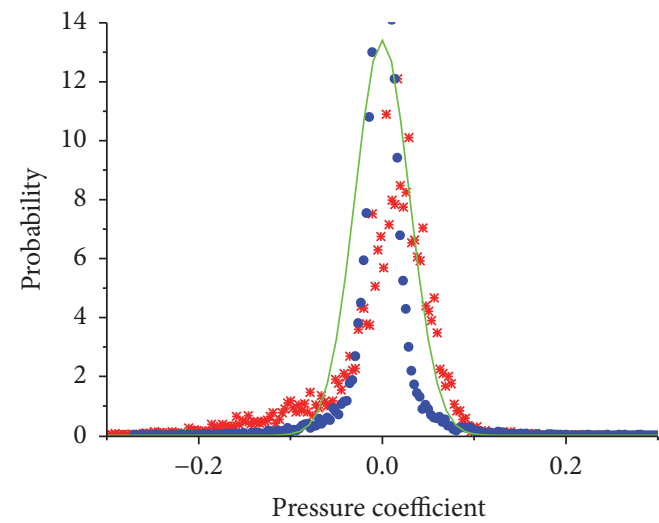

* Original full-scale

- Processed full-scale

- Gaussian distribution

(b) 30 degrees

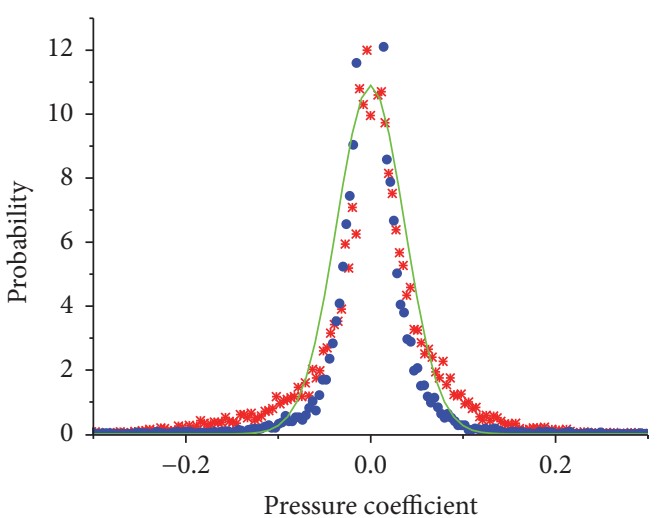

* Original full-scale

- Processed full-scale

- Gaussian distribution

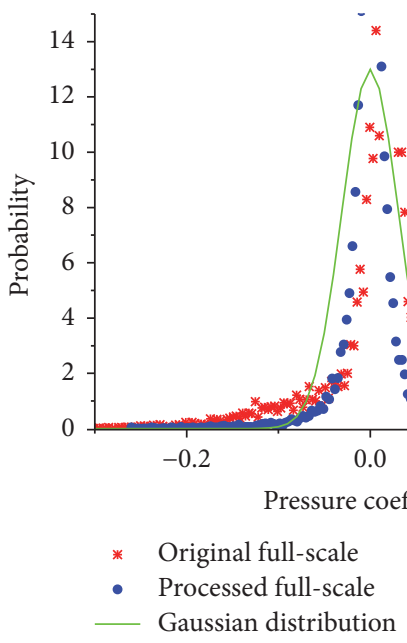

(d) 130 degrees

(e) 140 degrees

FIGURE 18: Probability density functions. 


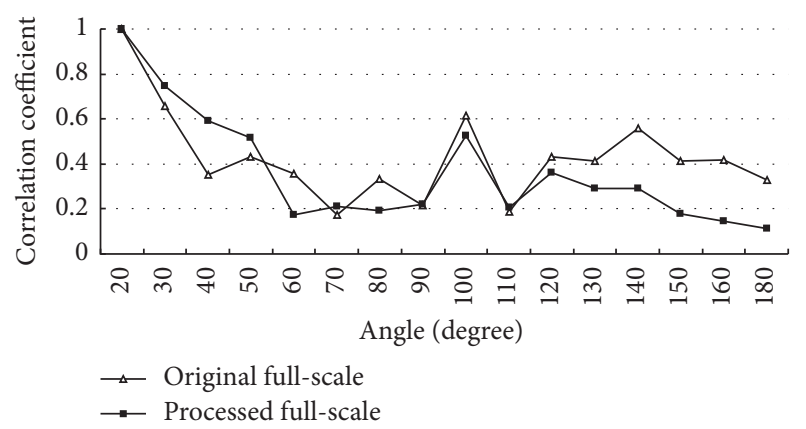

(a) 20 degrees-other positions

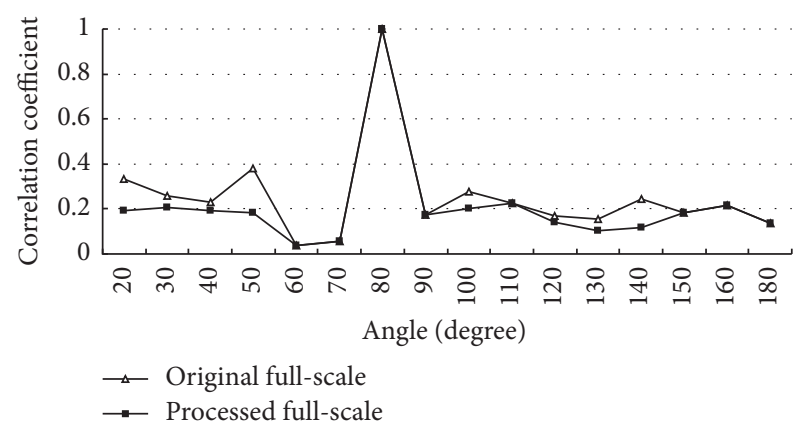

(b) 80 degrees-other positions

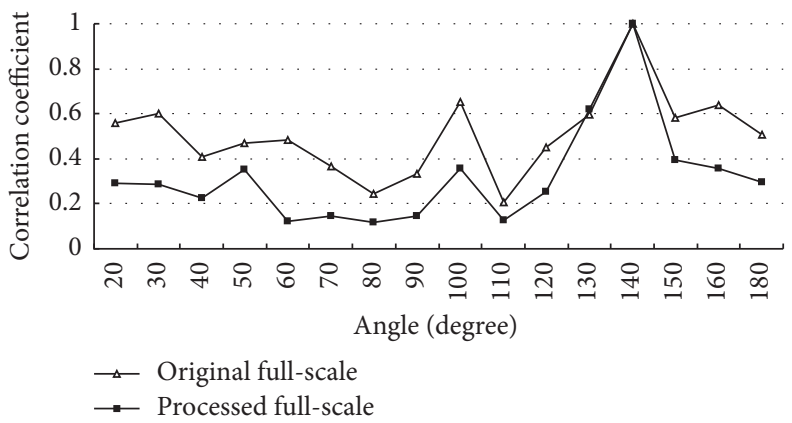

(c) 140 degrees-other positions

FIgURE 19: Correlation coefficients.

\section{Acknowledgments}

The authors gratefully acknowledge the supports of the National Natural Science Foundation of China (51178353 and 50978203), the National Key Basic Research Program of China (i.e., 973 Program) (2013CB036300), and China Postdoctoral Science Foundation.

\section{References}

[1] A. Kareem and T. Wu, "Wind-induced effects on bluff bodies in turbulent flows: nonstationary, non-Gaussian and nonlinear features," Journal of Wind Engineering and Industrial Aerodynamics, vol. 122, pp. 21-37, 2013.

[2] W. A. Dalgliesh, "Experience with wind pressure measurements on a full-scale building," in Proceedings of the Technical Meeting Concerning Wind Loads on Buildings and Structures, Gaithersburg, Maryland.

[3] X. Cheng, L. Zhao, Y. Ge, S. Ke, and X. Liu, "Wind pressures on a large cooling tower," Advances in Structural Engineering, vol. 18, no. 2, pp. 201-219, 2015.

[4] D. A. Jordan, M. R. Hajj, and H. W. Tieleman, "Wavelet analysis of the relation between atmospheric wind and pressure fluctuations on a low-rise building," Journal of Wind Engineering and Industrial Aerodynamics, vol. 69-71, pp. 647-655, 1997.

[5] C. P. W. Geurts, M. R. Hajj, and H. W. Tieleman, "Continuous wavelet transform of wind and wind-induced pressures on a building in suburban terrain," Journal of Wind Engineering and Industrial Aerodynamics, vol. 74, pp. 609-617, 1998.

[6] Y. L. Xu and J. Chen, "Characterizing nonstationary wind speed using empirical mode decomposition," Journal of Structural Engineering, vol. 130, no. 6, pp. 912-920, 2004.
[7] Q. S. Li and J. R. Wu, "Time-frequency analysis of typhoon effects on a 79-storey tall building," Journal of Wind Engineering and Industrial Aerodynamics, vol. 95, no. 12, pp. 1648-1666, 2007.

[8] P. Huang, X. Wang, and M. Gu, "Field experiments for wind loads on a low-rise building with adjustable pitch," International Journal of Distributed Sensor Networks, vol. 2012, Article ID 451879, 10 pages, 2012.

[9] N. E. Huang, Z. Shen, S. R. Long et al., "The empirical mode decomposition and the Hilbert spectrum for nonlinear and non-stationary time series analysis," Proceedings of the Royal Society of London. Series A. Mathematical, Physical and Engineering Sciences, vol. 454, no. 1971, pp. 903-995, 1998.

[10] E. Simiu and R. H. Scanlan, Wind Effects on Structures: Fundamentals and Applications to Design, John Wiley \& Sons, New York, NY, USA, 3rd edition, 1996.

[11] Ministry of Construction, P.R.C. (2003), GB/T 50102-2003: Code for Design of Cooling for Industrial Recirculating Water.

[12] J. S. Bendat and A. G. Piersol, Random Data: Analysis and Measurement Procedures, Wiley, New York, NY, USA, 2nd edition, 1986.

[13] H. Ruscheweyh, "Wind loadings on hyperbolic natural draught cooling towers," Journal of Industrial Aerodynamics, vol. 1, pp. 335-340, 1975/1976.

[14] S. Ke and Y. Ge, "Extreme wind pressures and non-gaussian characteristics for super-large hyperbolic cooling towers considering aeroelastic effect," Journal of Engineering Mechanics, vol. 141, no. 7, article 04015010, 2015. 


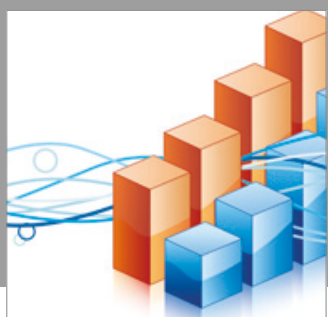

Advances in

Operations Research

vatersals

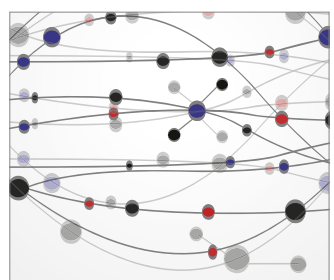

\section{The Scientific} World Journal
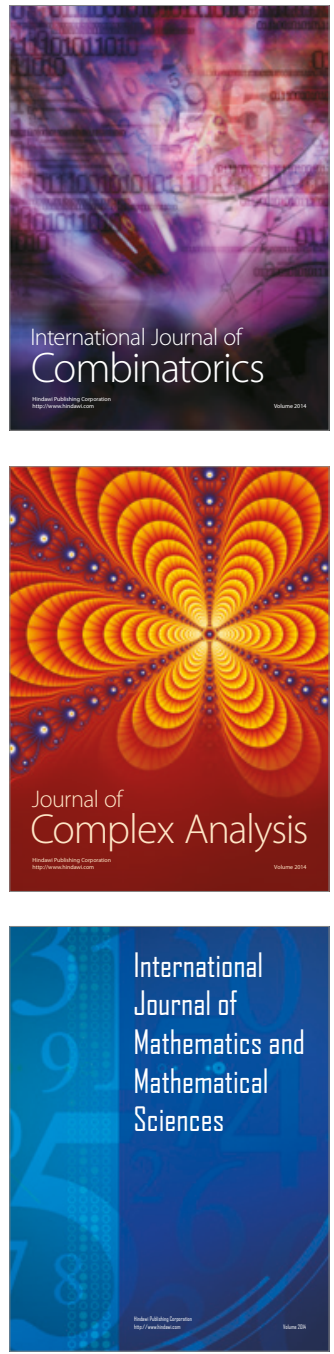
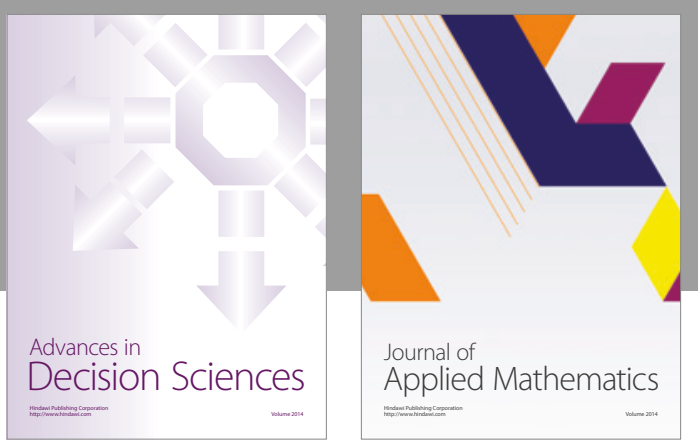

Algebra

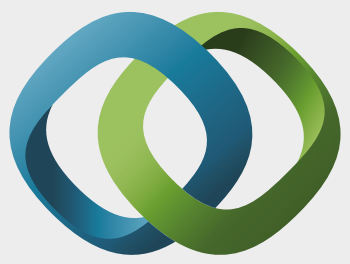

\section{Hindawi}

Submit your manuscripts at

https://www.hindawi.com
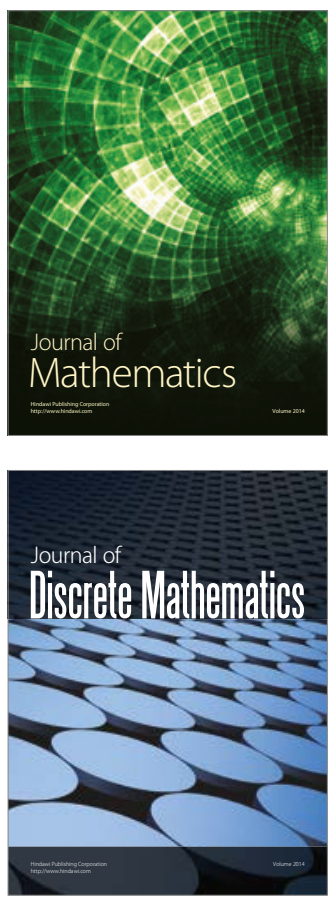

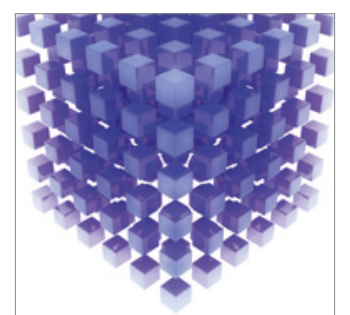

Mathematical Problems in Engineering
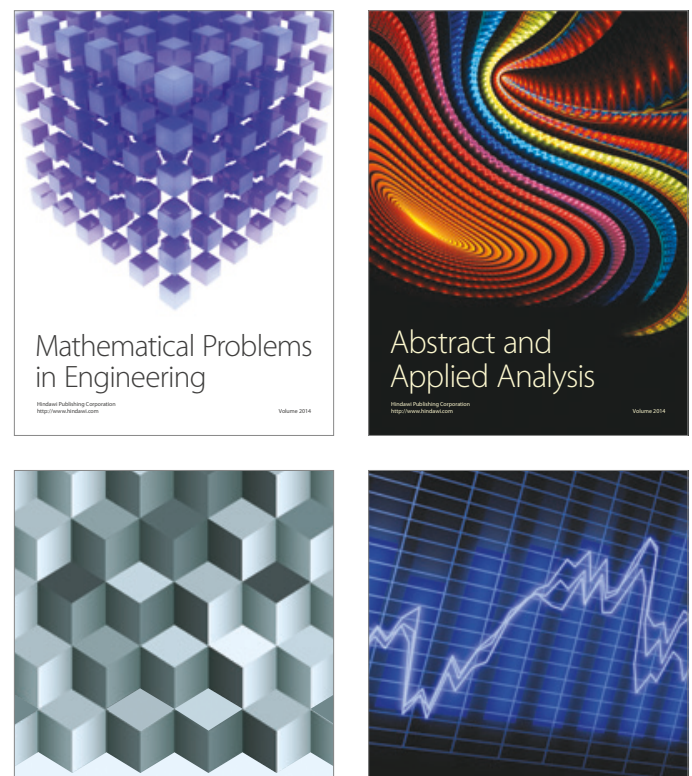

Journal of

Function Spaces

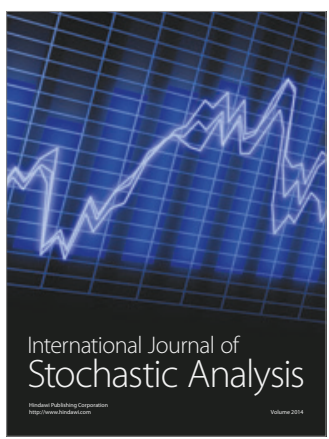

Probability and Statistics
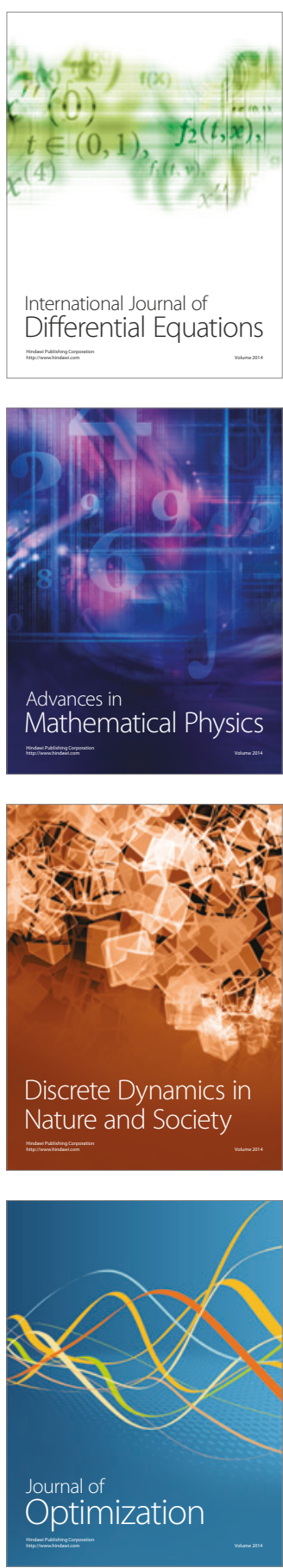